\title{
INDIVIDUAL BIBLIOMETRIC ASSESSMENT AT UNIVERSITY OF VIENNA: FROM NUMBERS TO MULTIDIMENSIONAL PROFILES
}

\author{
Evaluación bibliométrica individual en la \\ Universidad de Viena: de los números a los perflles \\ multidimensionales
}

Juan Gorraiz, Martin Wieland and Christian Gumpenberger

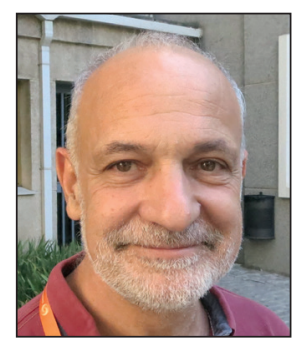

Juan Gorraiz studied physics at the University of Madrid and at the University of Vienna, where he obtained his doctor's degree. He is Head of the Department for Bibliometrics and Publication Strategies of the Library and Archive Services, University of Vienna, which is specialized on supporting both researchers and decision-makers in research administration. He has been engaged in bibliometric analyses and studies since 2001. He has been teaching information retrieval and bibliometrics at the university course Library and Information Studies since 1992. Apart from his ongoing commitment to the European Summer School for Scientometrics he was the organizer and programme chair of the $10^{\text {th }}$ Int I Conf on Science \& Technical Indicators 2008 in Vienna, as well as an organizer of the $14^{\text {th }}$ Int/ Society of Scientometrics and Informetrics Conf 2013 in Vienna. http://orcid.org/0000-0002-2414-3212

juan.gorraiz@univie.ac.at

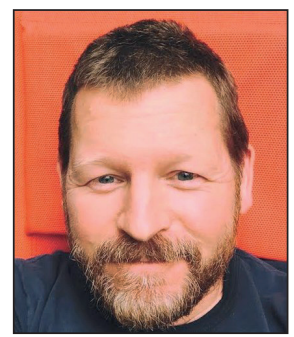

Martin Wieland studied at the Department of Social and Cultural Anthropology (University of Vienna) and specialised in Mongolian- and Gender Studies. He is founder and Head of a medical publishing company. Since 2008 he is also working at the Department for Bibliometrics and Publication Strategies, University of Vienna and has been involved in the set-up and developement of the European Summer School for Scientometrics from the start.

http://orcid.org/0000-0002-4912-3779

martin.wieland@univie.ac.at

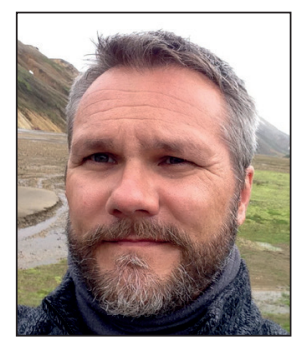

Christian Gumpenberger has a doctor's degree in veterinary medicine from the University of Veterinary Medicine Vienna and a master's degree in library and information studies from the Danube University Krems. He was Head of the Department of Public Services and Reference Librarians at the University Library of the University of Veterinary Medicine Vienna, Head of the Novartis Knowledge Center Vienna as well as global project manager for the Novartis Institutional Repository Project \& Open Access Champion at Novartis. He ran his own information consultancy business focussing on project management in the field of new trends in scholarly communication, especially open access. He is currently a Vice Head of the Department for Bibliometrics and Publication Strategies of the Library and Archive Services, University of Vienna and coordinator of the Council of Austrian University Libraries.

http://orcid.org/0000-0002-9188-8716

christian.gumpenberger@univie.ac.at

University of Vienna, Library and Archive Services, Bibliometrics and Publication Strategies Boltzmanngasse 5, A-1090 Vienna, Austria

\section{Abstract}

This paper shows how bibliometric assessment can be implemented at individual level. This has been successfully done at the University of Vienna carried out by the Department for Bibliometrics and Publication Strategies of the Vienna University Library. According to the department's philosophy, bibliometrics is not only a helpful evaluation instrument in order to com- 
plement the peer review system. It is also meant as a compass for researchers in the 'publish or perish' dilemma in order to increase general visibility and to optimize publication strategies. The individual assessment comprises of an interview with the researcher under evaluation, the elaboration of a bibliometric report of the researcher's publication output, the discussion and validation of the obtained results with the researcher under evaluation as well as further optional analyses. The produced bibliometric reports are provided to the researchers themselves and inform them about the quantitative aspects of their research output. They also serve as a basis for further discussion concerning their publication strategies. These reports are eventually intended for informed peer review practices, and are therefore forwarded to the quality assurance and the Rector's office and finally sent to the peers. The most important feature of the generated bibliometric report is its multidimensional and individual character. It relies on a variety of basic indicators and further control parameters in order to foster comprehensibility. Researchers, administrative staff and peers alike have confirmed the usefulness of this bibliometric approach. An increasing demand is noticeable. In total, 33 bibliometric reports have been delivered so far. Moreover, similar reports have also been produced for the bibliometric assessment of two faculties with great success.

\section{Keywords}

Individual bibliometric assessment; Publication strategies; Citation analysis; Individual evaluation; Bibliometrics.

\section{Resumen}

Se muestra cómo se puede implementar la evaluación bibliométrica a nivel individual, lo que se ha hecho con éxito en la Universidad de Viena, a cargo del Departamento Bibliometría y Estrategias de Publicación de la Biblioteca. De acuerdo con la filosofía del Departamento, la bibliometría no es más que un instrumento de evaluación útil con el fin de complementar el sistema de revisión por pares. También se entiende como una brújula para los investigadores en el dilema "publicar o perecer" con el fin de aumentar su visibilidad y para optimizar las estrategias de publicación. La evaluación individual se compone de una entrevista con el investigador evaluado, de la elaboración de un informe bibliométrico de las publicaciones del investigador, de una reunión y de una validación de los resultados obtenidos con el investigador, así como análisis adicionales opcionales. El informe bibliométrico se entrega al investigador, pues así éste conoce los aspectos cuantitativos de los resultados de su investigación. Adicionalmente, también se utiliza como base para discutir con él sus estrategias de publicación. Eventualmente, tal informe sirve para realizar la revisión por pares del investigador con más conocimiento de causa, y por lo tanto se reenvía a Aseguramiento de la calidad, a la oficina del Rector y finalmente a los pares. La característica más importante del informe bibliométrico es su carácter multidimensional e individual. Se fundamenta en varios indicadores básicos y otros parámetros de control con el fin de mejorar la interpretación. Tanto los investigadores, como el personal administrativo y los evaluadores han confirmado la utilidad de este enfoque bibliométrico, por lo que se ha producido una creciente demanda de los mismos. Hasta el momento se han entregado 33. Por otra parte, también se han realizado con gran éxito informes similares para la evaluación bibliométrica de dos facultades.

\section{Palabras clave}

Evaluación bibliométrica individual; Estrategias de publicación; Análisis de citas; Evaluación individual; Bibliometría.

Gorraiz, Juan; Wieland, Martin; Gumpenberger, Christian (2016). "Individual bibliometric assessment at University of Vienna: From numbers to multidimensional profiles". El profesional de la información, v. 25, n. 6, pp. 901-914.

https://doi.org/10.3145/epi.2016.nov.07

\section{Introduction and purpose}

In this paper we present an approach how bibliometric assessment has been implemented at individual level at the University of Vienna. This model has already been recognized and discussed at several occasions in various countries, and due to an increasing demand it is herewith made available on popular demand. Bibliometric assessment is generally the responsibility of the Department for bibliometrics and Publication Strategies of the Vienna University Library (in the following referred to as Bibliometrics Department). Since its launch in 2008, the mentioned department has already successfully completed 33 individual reports (Gumpenberger et al., 2012).

It is important to emphasize, that the tasks of the department are not only restricted to support university administration in their research assessment exercises, but also include supportive services for the scientists them- selves. Choosing the most successful publication channels is particularly important for the careers of young scientists.

Our Bibliometrics Department is committed to provide tailored services for these two beforehand mentioned target groups, the academic administration (Rector's office and Quality Assurance Department of our university, and the scientists themselves. Our primary concern is the prevention of "quick and dirty" bibliometrics and its consecutive incorrect and even harmful interpretations. We rather aim to achieve a situation with a well-informed administration on the one hand, and well-prepared scientists who can successfully cope with all these evaluation practices on the other hand.

The described approach was initially designed as a supportive bibliometric report for individual scientists. Such reports are intended to inform the scientists about the quantitative aspects of their research output and to serve as a basis for 
further discussion concerning publication strategies. Based on this service the scope has been expanded to an individual assessment of professors. At the University of Vienna, some professors need to undergo evaluation five years after their appointment due to the terms of their contract.

Depending on the discipline the rectorate decides whether or not the Bibliometrics Department should provide its bibliometric expertise. Such reports are only complementary to the professors' self-assessments and are always generated and finalised in mutual agreement between the Bibliometrics Department and the professors to be evaluated.

Once finalised these reports are checked by the Quality Assurance Department, then forwarded to the Rector's office and finally sent to the peers. By this means the latter hopefully refrain from performing inadequate bibliometric analyses and rather focus on the qualitative assessment (Weingart, 2005; Bach, 2011; Glänzel; Wouters, 2013).

Reports are intended to inform the scientists about the quantitative aspects of their research output and to serve as a basis for further discussion concerning publication strategies

The most important feature of a bibliometric report is its multidimensional and individual character. For each individual a personally elaborated report is tailored according to corresponding research field(s). This process includes the selection and use of the adequate data sources, the consideration of different publication cultures and publication channels, and the appropriate use of the available tools for analysis and presentation.

We are convinced that individual evaluation requires personalized treatment and cannot be achieved by automatized "push the button" evaluation reports. However, many of the currently available analytical tools are helpful to optimize and accelerate proper individual assessment.

Indeed, bibliometric analyses should never rely on only one particular indicator, since this normally means a restriction to only one aspect (Moed; Halevi, 2015). In spite of the fact that composite indicators aim to combine several aspects, they rather complicate than simplify the interpretation of the results for the addressed target group. Therefore, our approach relies on a variety of basic indicators and further control parameters, in order to do justice to the multidimensionality of the problem and to foster comprehensibility.

\section{General structure of the individual assessment}

The individual assessment comprises of the following steps:

- Interview with researcher under evaluation.

- Report or "bibliometric profile" of the researcher's publication output.

- Discussion and validation of the results with researcher under evaluation.

- Optional analyses.
Each of these steps is described and discussed in the forthcoming sections.

\subsection{Interview with the researcher under evaluation}

This is one of the most important and most relevant parts of the individual assessment. On the one hand, the bibliometricians and evaluators gain valuable insight into the researcher's work and the peculiarities of the corresponding research field. On the other hand, the researcher gets an opportunity to understand the applied evaluation methods and tools and to discuss suitability and restrictions.

The most important feature of a bibliometric report is its multidimensional and individual character

Scientists tend to be busy and certainly cannot spare too much time for interviews. In order to stress the importance and to guarantee availability, the Rector's office invites the researchers to participate actively in the evaluation process.

Interviews can last from one to two hours (at most) and generally take place at the researchers' workplaces. The following questions are always asked:

1. Which data sources do you use regularly for retrieving literature in your research field? Do you use alert services?

2. Do you use permanent person identifiers (like orcid, ResearcherlD, etc.)?

3. Do you have a complete record in our Current Research Information System (CRIS)?

4. Do you use repositories?

5. Have you submitted preprints in order to claim priority?

6. What are the most important publication channels in your field (special emphasis on monographs, book chapters, patents if appropriate)?

7. Does the order of authors (first, last or corresponding author) play a role in your research field? If no, why not?

8. Which criteria are relevant for your publication strategy?

9. Is Open Access also a valid criterion according to the recommendation of our university? If no, why not?

10. Do you actively participate in conferences?

11. Are you an editor of one or more scientific journals? If yes, which ones?

12. Do you actively support the peer-review system by providing reviews? If yes, how many per month?

13. Do you maintain a personal website? An entry in Wikipedia? A Google Scholar Citations profile?

14. Do you use a reference manager system? If yes, which one? Why do you think it is helpful?

15. Do you actively engage in mailing lists or blogs? If yes, which ones?

16. Do you use other social media tools? If yes, which ones? 
17. What do you think about usage metrics (downloads) and altmetrics?

18. Do you generate research data? If yes, how do you manage and archive them?

19. How do you (or would you) select and assess colleagues or potential collaborators? If yes, do you also embrace quantitative methods?

20. Is there anything else we have not covered so far and you would like to share?

Questions 1 and 6 are crucial for the selection of the data sources used for the bibliometric analyses, whereas questions 2 and 3 are relevant for data disambiguation. Question 7 informs about the need for such an analysis. However, this will also be checked in the databases independent from the interviewee's feedback.

Questions 4, 5, 8 and 9 are relevant for the design of the visibility analysis.

Questions 10, 11 and 12 inform about the researcher's experience and reputation in the field. Questions 13 until 17 are relevant in order to learn about the researcher's attitude to new metrics and social media.

Question 18 has been included since research data management is an emergent topic (Costas et al., 2012; Bauer et al., 2015).

Responses to questions 19 and 20 finally allow to meet the researcher's particular expectations.

\subsection{Bibliometric report}

Publication data are provided by the researcher under evaluation in form of a publication list as agreed in the previous interview. The list is compared to the data retrieved in the bibliometric data sources by the bibliometricians and amended if necessary.

The resulting bibliometric report itself is custom-tailored for each professor according to individually relevant aspects and to the accepted publication culture in the according discipline.

The structure of the bibliometric report generally comprises of the following sections:

- Methodology

- Coverage in databases

- Activity analysis for publications

- Affiliation and funding analyses

- Co-authorship analysis

- Visibility analysis

- Impact analysis

- Citing analysis

- Network and cooperation analysis

- Reference analysis

- Research focus

- Summary

- Annex

Each section will be described in full detail to foster a better understanding of our approach.

\subsubsection{Methodology}

The methodology section includes a thorough description of the databases and indicators selected for the bibliometric analysis.

As it is already a well-established practice at the University of Vienna (Gumpenberger et al., 2012: Gorraiz et al., 2015), the bibliometric standard analyses are meant to shine a light on three different main aspects:

Activity: the number of publications along a timeline and with differentiation of document types to reflect the productivity (Lotka, 1926). Furthermore, authorship and affiliation analyses (like number of co-authors or author's role) are provided as well (Shockley, 1957).

Visibility: the percentage of publications indexed in well-respected databases (see coverage) as well as the prestige and impact of the journals where the researcher has published in, according to the Journal Impact Factor (Garfield, 2005; Glänzel; Moed, 2002) or other alternative journal impact measures such as SCImago Journal Rank (SJR) (GonzálezPereira et al. 2009) and Source Normalised Impact per Paper (SNIP) (Moed, 2010; 2011), in order to reflect the editorial barrier and to unveil publication strategies.

Visibility plays a key role whenever the evaluation covers only the most recent years. In this case, the citation window is too short and the relevance of such citation analyses is limited. Furthermore, higher visibility increases the chance to be cited.

Impact: a citation analysis including several indicators to reflect the significance in the scientific community (Cronin, 1984; Van Raan, 2004; Moed, 2005; De Bellis, 2009; Vinkler, 2010).

In spite of the fact that composite indicators aim to combine several aspects, they rather complicate than simplify the interpretation of the results

Tables 1 and 2 inform about the aspects of a bibliometric profile and its corresponding indicators

Additionally, an analysis of the citing documents (see impact Table 1), of the research focus and interdisciplinarity (see Focus), of the cooperation networks at different levels (see Table 2) and of the cited references (see Knowledge base) are provided. "Other metrics" and "Self-marketing in Internet" are discussed in the sections "Interview" and "Optional analyses".

It cannot be stressed often enough that citations are only used as a proxy for the impact (and not for the quality) of the publications in the "publish or perish" community (i.e. the researchers who are committed to publishing their results).

Visualization is done with the freely available software packages BibExcel (Persson et al., 2009), Pajek (De Nooy et al., 2005) and VOSviewer (Van Eck; Waltman, 2010). In the resulting maps the size of the circles is proportional to the 
Table 1. Dimensions and indicators (part 1 )

\begin{tabular}{|l|l|l|l|}
\hline \multicolumn{1}{|c|}{ Activity } & Visibility (publication strategies) & \multicolumn{1}{|c|}{ Impact (citations) } & \multicolumn{1}{|c|}{ Focus } \\
\hline \# Publications \& Trend lines & \# indexed in databases (coverage) & \# citations (total, mean, maximum) & $\begin{array}{l}\text { maps based on titles \& abstracts, } \\
\text { descriptors, keywords and iden- } \\
\text { tifiers }\end{array}$ \\
\hline \# Document types & \# \& \% English & $\begin{array}{l}\text { Normalised Citation Score (CNCl, } \\
\text { Crown-Indicator) }\end{array}$ & $\begin{array}{l}\text { Inter- and multidisciplinarity } \\
\text { according to WoS/Scopus subject } \\
\text { categories }\end{array}$ \\
\hline $\begin{array}{l}\text { \# Authors (mean, maximum, \# } \\
\text { single-authored) }\end{array}$ & $\begin{array}{l}\text { \# in Top journals (according JIF. SJR, } \\
\text { SNIP or journal's lists or rankings) }\end{array}$ & $\begin{array}{l}\text { \# \& \% Tops in Percentiles (Top 1\%, } \\
\text { Top 10\%) }\end{array}$ & \\
\hline $\begin{array}{l}\text { \# Author's role (first, last, cor- } \\
\text { responding) }\end{array}$ & $\begin{array}{l}\text { aggregate \& median category } \\
\text { impact factor }\end{array}$ & $\begin{array}{l}\text { h-index \& variations (g,m); } \\
\text { i-indices }\end{array}$ & \\
\hline \# patents & \# Open access & \% self-citations & \\
\hline \# research data sets? & books? & analysis of citing documents & \\
\hline
\end{tabular}

number of publications, whereas the width of the lines is proportional to the strength of their co-occurrence (Figures 1 and 2).

\subsubsection{Coverage analyses}

Coverage analyses have two main purposes: first, to select the adequate data sources for the forthcoming analyses, and second, to shed light on the visibility of the research performance.

This second aspect is based on the fact that publications indexed in international renowned databases are more visible than the non-indexed ones, and that they can be retrieved more easily.

The Web of Science (WoS) Core Collection is used as the preferred data source for bibliometric analyses, since being indexed in this database is generally perceived as a sort of "high impact" (or at least high visibility) criterion within the scientific community. All the faculties related to the natural sciences have corroborated this perception.

Analyses are performed in the source part as well as by using the cited reference search, especially for other document types than contributions in journals.
Due to the fact that not all disciplines are equally well covered in WoS, alternative data sources such as Scopus or Google Scholar are used for complementary analyses.

Scopus is used as second citation database, in order to avoid or correct indexing errors in WoS and to benefit from the larger number of indexed journals (almost twice as many as in WoS).

Google Scholar $(G S)^{1}$ via "Publish or Perish"2 (Harzing, 2007) is considered as a complementary bibliometric source. It stands out because of its higher coverage for some publication types (like monographs, reports, etc.), which are more relevant in the social sciences and the humanities.

This set of data sources is always complemented with at least one subject specific database. The choice is made based on the preference of the researcher under evaluation. Such popular additional databases are, for instance, Chemical Abstracts or Mathematical Reviews.

However, for citation analyses only products are considered that include the corresponding metrics or at least citation counts.

Table 2. Dimensions and indicators (part 2)

\begin{tabular}{|c|c|c|c|}
\hline Cooperation & Other metrics & Knowledge base & Self-marketing (Internet) \\
\hline $\begin{array}{l}\text { based on affiliations: intensity (\# } \\
\text { publications) \& impact (\# citations, } \\
\text { cits/publ, CNCl, \% Top10\%, \%Top } \\
1 \% \text { ) }\end{array}$ & usage metrics: views \& downloads & $\begin{array}{l}\text { reference analyses (cited docu- } \\
\text { ments) }\end{array}$ & in repositories \\
\hline $\begin{array}{l}\text { \% international collaboration } \\
\% \text { domestic collaboration } \\
\% \text { industry collaboration }\end{array}$ & $\begin{array}{l}\text { altmetrics (captures, mentions, } \\
\text { social media, etc.) }\end{array}$ & $\begin{array}{l}\text { state-of-the-art (PY of cited } \\
\text { documents), most cited document } \\
\text { types, most cited journals, most } \\
\text { cited papers }\end{array}$ & in Google Scholar, in Wikipedia \\
\hline $\begin{array}{l}\text { network analyses at various } \\
\text { levels (scientists, institutions and } \\
\text { countries) }\end{array}$ & & $\begin{array}{l}\text { benchmarking with other leading } \\
\text { scientists in the same research field }\end{array}$ & $\begin{array}{l}\text { in mailing lists, blogs, reference } \\
\text { managers and other social media } \\
\text { tools }\end{array}$ \\
\hline
\end{tabular}




\subsubsection{Activity analyses for publications}

The first activity analysis is performed according to the publication list provided by the researcher under evaluation itself.

The most important publication types and document types are identified.

Document types used by the authors in their publication lists are manually reassigned to these generally included standard groups: monographs (books), book chapters, journal articles, proceedings papers, conferences (including meeting abstracts and talks), book reviews, edited books and journal issues, and other publications (or miscellaneous). Reports or working papers and patents are included whenever appropriate, mostly for disciplines related to physics, the life sciences or technology.

Some publication types occasionally receive special attention according to their disciplinary importance, such as proceedings papers in computer sciences or book reviews in the social sciences.

Different document types and publication windows are distinguished in the results of the activity analysis. The standard analysis contains a chart providing the evolution of the past ten complete years. This is done for all document types as well as for the most important document types (articles, citable items, etc.). Information about earlier years or the most recent uncompleted year is provided separately.

The activity or productivity is measured by means of absolute output values -that is, normal counts. In order to relativize the obtained results, complementary co-authorship analyses are performed.

Data automation is desirable, but currently no automation can deliver the same reproducible results. Therefore we attach special importance to the degree of coverage in the databases used for our analyses and match the obtained search results with the provided publication lists whenever possible. Automation will gain momentum once a critical mass of permanent individual identifiers (like orcid) has been implemented within the scientific community.

\subsubsection{Co-authorship analysis}

The total number, the average number (mean and median) and the maximum number of co-authors are determined for various periods in order to analyze their progress in time (Laudel, 2002; Glänzel, 2014). Furthermore, the number and percentage of single authored publications as well as the author's publication role (number and percentage of publications where the researcher is first, last and/or corresponding author) are studied for different periods.

The order of authors is mostly determined by the degree of contribution, but can also by alphabetical in some fields. The initial interview with the researcher under evaluation sheds light on this issue, and all provided information is easily corroborated by the bibliometric analysis.

\subsubsection{Affiliation and funding analyses}

Correct affiliation information enhances institutional visibility and directly influences the position in university ran- kings. Most rankings rely on data from WoS or Scopus. Therefore, affiliation analyses are usually performed in these databases.

Affiliation changes and how these might affect the productivity of a researcher are also considered in this type of analysis.

Funding analyses are also performed in order to inform about the number and percentage of funded publications as well as the main funding agencies. These analyses are performed in WoS and Scopus and offer quite reliable results since 2008.

\subsubsection{Visibility analysis}

The visibility analysis comprises of two parts: first, the number and percentage of publications indexed in the international, well-respected selected data sources as already mentioned under coverage analysis, and second, the number and percentage of publications in top journals or sources.

The visibility of a document is determined by the reputation or the impact of the source where it was published. It reflects the editorial barrier and unveils publication strategies.

Therefore, the journals or sources where the researcher under evaluation has published in are analysed and compared for various time periods.

For a journal article, the visibility can be determined by the impact measures of the journal it was published in. The most common impact measure is the journal impact factor (JIF) (Garfield, 2005; Glänzel; Moed, 2002). Thus, a document has a high visibility in one research field, if it was published in a journal with an JIF bigger than the aggregate or the median JIF of the corresponding subject category or field. Therefore, visibility can be quantified by the JIF of the source in relation to the aggregated or median JIF assigned to the corresponding subject category.

The JIF is an appropriate visibility measure, but only for journals indexed in the Journal Citation Reports (JCR). Other recent alternatives are based on the widely known PageRank algorithm of the Google search engine - for example, the article influence score or the SJR indicator (GonzálezPereira et al., 2009). SJR and SNIP (Moed, 2010; 2011) refer to journals indexed in Scopus, which results in a considerable increase of "visible" journals to almost 21,000 journals.

The JIF of the most recent JCR edition is used for all analysed publications as an accepted compromise. ${ }^{3}$ In our approach, we predominantly use JIF quartiles. The quartiles (Q1 = Top 25\%, Q2 = Top 25-50\%, Q3 = Top 50-75\%, Q4 = Top 75-100\%) in the corresponding Web of Science category ${ }^{4}$ are calculated based on the JIF data reported in the last available edition of the Journal Citation Reports (JCR) in the corresponding Web of Science category (impact of the journal at the time of the evaluation).

Due to the fluctuations of the JIF, discrepancies are expected according to the method employed. However, the use of quartiles addresses these shortcomings significantly, because the quartiles are less volatile (Gorraiz et al., 2012b).

The visibility analysis includes the list of all journals and seri- 
als, where the scientist under evaluation publishes in. The following aspects are taken into account:

1) The number of items published in the last ten years.

2) The number of citations attracted by the publications in each journal.

3) The corresponding journal impact measure (JIF, Article influence score, SNIP, SJR).

4) The corresponding quartile according to the selected journal impact measure.

Furthermore, the allocation of all publications (2005-2015) to the different JIF quartiles and the comparative quartiles distribution for the publications either published in the interval 2005-2009 or 2010-2014 are calculated and plotted in figures. These analyses are performed in order to reveal considerable changes in the publication strategy and journal preferences in the previous five years.

In disciplines where the coverage in WoS and Scopus is known to be low, such as in the social sciences, mathematics and the computer sciences, committees and faculties have the possibility to provide self-compiled lists of "highly" reputed journals for their discipline. In such cases, the number of publications in these selected journals is calculated.

Unfortunately, it is much more difficult to assess the visibility of monographs (see Table 1). Such analyses for publication types like edited books or monographs are highly controversial. Reputation of the editorial board, circulation, number of editions, holdings and loans in international catalogues are the most relevant indicators suggested, but none of these so-far suggested approaches has proven to be suitable for research assessment purposes.

Finally, the number and percentage of OA publications (green, gold and hybrid) are retrieved. It is particularly useful to check the compliance with adopted institutional policies (OA policy, affiliation policy, etc.) or the success of selfdeveloped publication strategies in the case of individuals.

Visibility analyses are NEITHER used to assess the quality NOR the impact of single publications. They are rather meant to assess the reputation or impact of the sources in which original research was published. Therefore, they are suggested as an alternative approach and are meant to supplement traditional citation analyses for evaluative purposes. They are especially helpful, whenever assessment exercises are performed for the last, most recent years, meaning that the citation window is too short for retrieving a significant number of citations in many disciplines. This is particularly true for fields with a long cited half-life, as it is usual in the social sciences and in the humanities.

Visibility analyses based on journal impact measures can only tell a part of the whole story. In order to paint a more complete picture it is nowadays possible to exploit the wealth of scholarly communication channels available on the Web, which is particularly promising for the social sciences and the humanities. Publication strategies related to alternative data sources and metrics will be addressed as well as the use of individual permanent identifiers (orcid, etc.) and correct affiliations.

\subsubsection{Impact analysis}

Impact finally relies on citations as proof of recognition within the scientific community.

Citation analyses for publications in journals are commonly performed in the source part of WoS. However, the "cited reference search" is also used in order to collect citations to other document types that are not indexed in the source part of WoS, particularly if these document types are common publication channels of the researcher under evaluation.

In order to consider the skewness of most of the citation distributions (Seglen, 1992), three indicators are used to describe the distribution of citations: the total sum, the arithmetic mean and the maximum ${ }^{5}$. Furthermore the number or percentage of cited documents is considered and the arithmetic mean substituted by the number of citations per cited document, which is a more significant indicator. Moreover, the $\mathrm{h}$-index is determined for all document types (Hirsch, 2005; Bar-llan, 2008; Alonso et al., 2009).

Citation analyses are performed for citable items (articles, reviews and proceedings papers) as well as for all items (Gorraiz; Gumpenberger, 2015). The percentage of selfcitations (Glänzel et al., 2004; 2006) is calculated and included as "Control data". Values below 20\% are considered as normal, whereas higher ones have to be explained.

Citation counts are an accepted proxy for impact. However, normalisation is needed according to discipline and per publication year (Schubert; Braun, 1986; 1996; Costas et al., 2009). Our multifaceted approach is based on the usual indicators (citations, citations per cited publication, maximum of citations, h-index and g-index), but also incorporates normalised citation counts in the form of the "Category Normalized Citation Impact" $(\mathrm{CNCl})^{6}$ and the number and percentage of Top 10\% and Top1\% most cited publications (Adams et al., 2007; Gorraiz et al., 2011; 2012a; Bornmann et al., 2012). Top $10 \%$ is used in order to assess the degree of excellence and Top $1 \%$ allows a further differentiation between highly cited ("excellent") and extremely highly cited publications ("edgy" publications).

$\mathrm{CNCl}$, Top $10 \%$ and Top $1 \%$ most cited publications can be calculated according to the Clarivate's Essential Science Indicators (ESI) percentiles (22 categories) or by using the Clarivate's InCites tool, which enables different calculations to include other classifications or the corresponding WoS categories (more than 250). In this latter case, fractional count is used when the journal is assigned simultaneously to various WOS categories.

Citation analyses are mostly performed in WoS Core Collection, Scopus and in at least another subject specific database with included citation counts (like ADS, HEP, Mathematical Reviews, Chemical Abstracts, Biosis, etc). Google Scholar (via "Publish or Perish" and/or Google Scholar Citations Profiles) has so far been used in an exploratory way for the humanities and the social sciences.

Field normalized indicators based on reference values are not available in WoS cited reference search or in Google Scholar (data sources not providing reference citations va- 
lues per subject category and year of publication) and were then substituted by variations of the $\mathrm{i}$-index (some variations of the i-index, starting with the $i 10^{7}, \mathrm{i} 50, \mathrm{i} 100$, and i100), according to the number of citations attracted in each source. It should also be considered that the "i-index" thresholds are determined according to the expected number of citations for each discipline. Therefore, in the social sciences, only the i10-index and the i50-index are common.

Citation analyses for monographs relying on both the Book Citation Index and the "cited reference search" in WoS are performed separately in order to avoid inconsistencies by mixing different metrics (Gorraiz et al., 2013).

If appropriate and desired by the researcher under evaluation and in consideration of the previous interview, further document types such as patents, e-publications, articles in newspapers, etc., are also taken into account. Patent analyses are performed in Espacenet at the EPO, or for some fields (like chemical, engineering, electrical and electronic and mechanical engineering) in Derwent Innovations Index or in Chemical Abstracts.

\subsubsection{Analyses of the citing documents}

All citing articles are retrieved in WoS using the citation report. Another possibility is to enlarge the analysis to the cited reference search in order to include also citations to non-indexed publications in Web of Science Core Collection.

Mainly two analyses are performed.

First, the citing countries, institutions, authors and journals are determined. ${ }^{8}$
For example, a network map of the citing countries informs about the degree of internationalisation concerning the impact of the researcher under evaluation (e.g. see figure 1).

The size of the circles is proportional to the number of publications; the width of the lines is proportional to the strength of their co-occurrence.

Second, the citing publications can also be analysed according to:

a) Their visibility: percentage of top journals citing publications of the researcher in evaluation

b) Their impact: $\mathrm{CNCl}$, percentage of Top $10 \%$ and Top $1 \%$ most cited among the citing documents.

These results, especially the ones from the first part, are then compared to the ones resulting from the cooperation and reference analyses (see next sections).

\subsubsection{Cooperation analyses}

Primarily, the proportions of international, national and domestic collaboration and their time evolution are analysed (Persson et al., 2004).

Further analyses are then performed at country, affiliation and author levels.

\subsubsection{Cooperation on country level}

An international network on country level is shown in this example of a corresponding network map (see Figure 2).

This cooperation map is compared with the impact map created in section 2.2.8 and clearly shows that impact is normally much broader than pure collaboration. Thus the map representing the citing countries has more vertices and a higher density. In principle, this analysis could also be performed on affiliation or author level (considering e.g. citing institutions versus cooperating institutions, see also 2.2.9.2).

\subsubsection{Cooperation on affilia- tion level}

An overview of the most cooperative institutions is provided in a table, which includes institution name, country name, the number and percentage of shared publications, the number of citations attracted, the $\mathrm{CNCl}$ (see 2.2.7), the percentage of Top $10 \%$ and Top $1 \%$ most cited publications, the percentage of international collaboration and the percentage of collaboration with industry. Most of these data are obtained via InCites.

The number and percentage of shared publications informs 
about the volume or intensity of the cooperation, the number of citations attracted about the total impact of the collaboration, the $\mathrm{CNCl}$ and the percentage of Top $10 \%$ and Top $1 \%$ most cited articles about the mean impact and the excellence respectively.

The produced table shows that the most collaborative institutions (highest number of co-publications) are not always responsible for the highest $\mathrm{CNCl}$ scores and the highest percentage of top publications.

\subsubsection{Cooperation on author level}

A map informs about the network on author level. The number of different coauthors as well as the most collaborative authors can be identified.

"Co-author dependence" (i.e. percentage of publications with the same coauthor) is always reported especially when it exceeds $75 \%$.

\subsubsection{Reference analyses}

The reference analyses inform about the knowledge base of the researcher under evaluation. They reveal which sources have been used and cited.

The total number of cited references, the percentage of cited journals or serials and the percentage of citations to other discipline-specific publication types are determined. These calculations are all performed by means of the software package BibExcel as well as by further manual disambiguation.

Moreover, the state-of-the-art (publication years) of the cited references is represented in a figure. The publication years of the cited references are then compared with the cited half-life in the corresponding research field. Figure 3 shows an example.

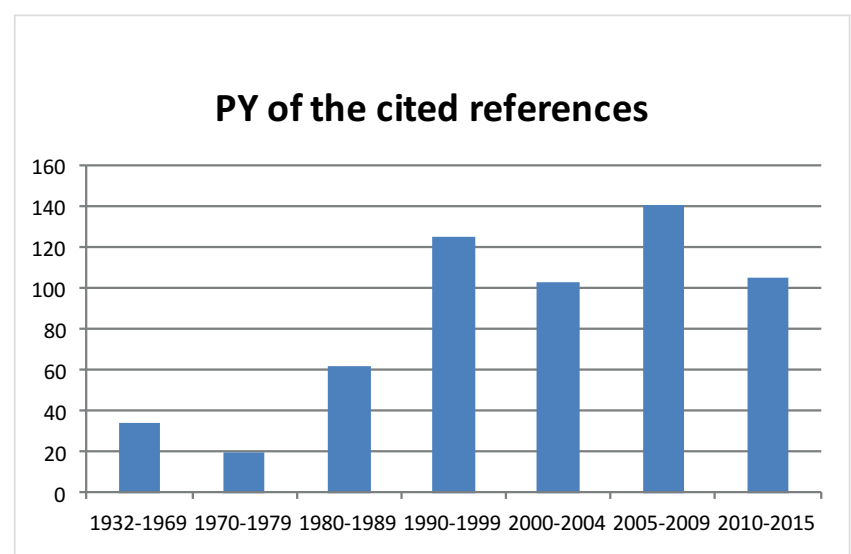

Figure 3. State-of-the-art (publication years) of the cited references
The most cited sources and journals are determined, analysed (percentage of top journals) and compared with the journals, where the researcher under evaluation uses to publish in (see visibility analysis). Researchers are expected to successfully publish to a great extent in the top journals, which they also cite regularly and which constitute their knowledge base.

A big match is a strong indication that the scientist under evaluation has managed to publish in the most relevant sources of his research area.

In order to assess the author's publication strategy, two aspects are analysed. First the congruence of the lists, which means, if an author tends to publish in the same journals that he/she cites and if the authors is cited in the same journals where he/she publishes. The second measure refers to the overlap by quartiles.

This analysis also helps to identify the most relevant sources in highly specific research fields, which is useful for correcting apparent limitations of subject classifications (Glänzel et al., 2016).

\subsubsection{Research focus}

Term-based co-occurrence maps are helpful to identify the most important research topics and the research focus of the researcher under evaluation. Terms are extracted from the title and abstract fields from WoS or Scopus publications. Co-occurrence maps can then be created with the tool VOSviewer (see example, Figure 4). A minimum number of occurrences of a term is determined as a threshold. 


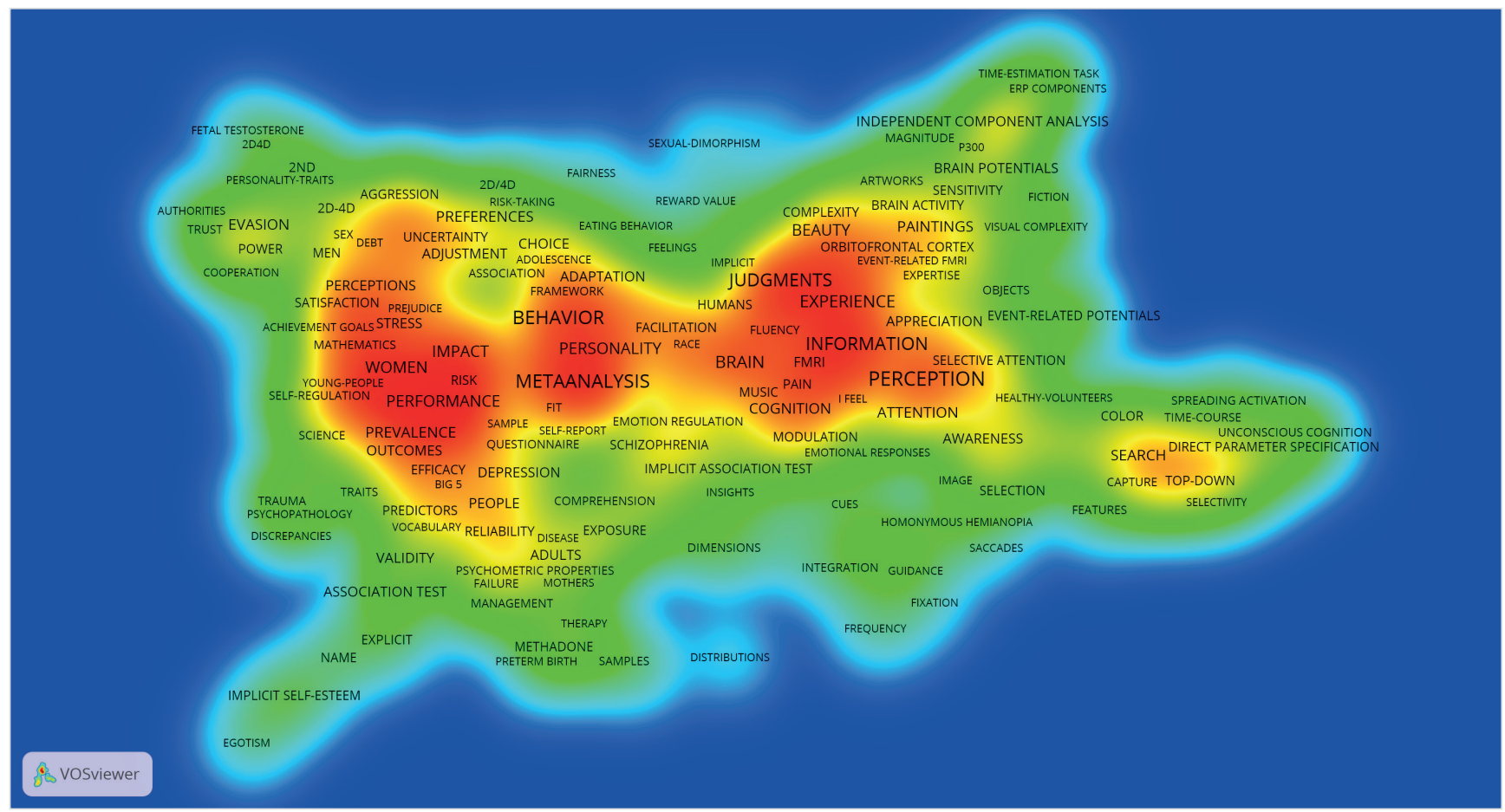

Figure 4. Co-occurrence map created with VoSviewer

Subsequently a relevance score is calculated based on the field "times cited". According to this score, the $60 \%$ or $70 \%$ most relevant terms are selected.

More specific maps can be obtained by using controlled vocabulary (descriptors and identifiers) instead of terms extracted from the title and abstract fields. Preferably, cooccurrence maps were generated for each time period using the field "Keywords Plus ${ }^{\circledR}$ ", available in WoS Core Collection, labelled as ID and which consists of words and phrases harvested from the titles of the cited articles, as reported in the database.

The resulting maps are compared and discussed.

\subsubsection{Summary and annex}

The most important results of each section of the bibliometric profile are wrapped up in order to allow a fast overview. All the data are provided in an annex, in order to guarantee the transparency of the method.

\section{The bibliometric report is only used in order to provide a quantitative descrip- tion of the research output, to reveal potentially meaningful symptoms and to discuss them with the researcher under evaluation}

\section{Discussion and validation of the results with the researcher under evaluation}

The bibliometric report is always discussed with the researcher himself before it is handed over to the quality assurance, the Rector's office and the peers. It complements the researcher's qualitative self-evaluation report and must not be taken out of this context.

It should be stressed that the bibliometric report is only used in order to provide a quantitative description of the research output, to reveal potentially meaningful symptoms and to discuss them with the researcher under evaluation.

Of course, researchers might always have good reasons for their choices of publication channels and responses for other questions arising from this quantitative report (e.g. periods of low activity, author role, low degree of international collaboration, etc.) and they are invited to clarify them in their own additional evaluation report for the peers.

\section{Optional analyses}

Last, but not least, three optional analyses are offered.

The first one is related to the research focus. With the researcher's help, his research field is delineated in one database, preferably in Web of Science or Scopus. The researcher is advised to save the resulting search string in order to create an alert service and to be automatically notified about any forthcoming relevant publications in his topic.

Based on the search results, the most important key actors of the last ten years are identified: most active authors and institutions, as well as funding agencies. Then the most cited publications and most cited first authors are retrieved and/or plotted in a map (bibliographical coupling). Finally, the top most cited publications (Top 10\% and Top 1\%) are identified.

The second analysis addresses the exploration of references. The researcher is asked to choose three leading peers in his research field (this can be based on the data retrieved from the previous optional analysis if available). The 
researcher's output will be then compared to the output of these selected peers for the last 10 years, including visibility, impact, cooperation and focus analyses as already pointed out before. Additional value is now created by doing a reference analysis. The most cited references are identified for the selected peers and then compared with the most cited ones of the researcher under evaluation. The researcher can then decide whether or not these sources are relevant for him, and if deviations are intentional or not. This type of analysis provides valuable insight on how to enhance one's knowledge base.

Bibliometrics should be perceived as a compass for researchers in the 'publish or perish' dilemma in order to increase general visibility and to optimize publication strategies

The third analysis is related to assessing the societal impact or the impact on the web (Galligan et al., 2013; Konkiel, 2013; Bornmann, 2014; Haustein et al. 2014). For this purpose, we currently explore two tools, altmetric.com and PlumX, sometimes even complemented by data retrieved from Scopus.

Publications are mainly analysed by using the DOI of each publication, but also by means of other options like the URL, ISBN, patent number, etc. depending on the selected tool.

Most of our analyses were so far performed with PlumX. It allows a differentiation between citations (in Pubmed and Scopus), usage data (Ebsco, etc.), captures and mentions.

\section{Retrospective overview of the bibliometric assessment}

The usefulness of the bibliometric assessment has been confirmed by all the positive feedback obtained from researchers, research managers and peers on the one hand, and by an increasing demand on the other hand. After a pilot phase in 2010, the assessment service started in 2011 with eight bibliometric profiles and increased steadily since then to ten in 2014 and 15 in 2015. In total, 33 bibliometric reports have so far been delivered. For 2016, the Rector's office has already commissioned more than 30 further reports.

Table 3 gives an overview of the research fields analysed. It shows that $75 \%$ of the bibliometric reports refer to research fields related to Natural or Life sciences, and $25 \%$ to the ones related to Social sciences.

The most used data sources were WoS Core Collection, Scopus and Google Scholar. According to the research field, other databases were also used, like: MathSciNet (Mathematics), ADS and Inspire-HEP (Astrophysics, Particle and Gravitational Physics), Sociological Abstracts and EBSCOhost (Sociology), ADS (Computer Science) and RePEc (Research Papers in Economics, including CitEc). As already mentioned above, the selection of the data sources was previously discussed and agreed with the scientist himself.
The bibliometric analyses were generally performed within two or three days by two colleagues from the Bibliometrics and Publication Strategies Department, depending on the number of considered data sources. Most of this time was spent on thorough data disambiguation and data cleaning. Candidates with implemented personal identifiers such as orcid (Open researcher and contributor ID) or Thomson Reuters ResearcherID were definitely quicker to assess, provided that the profiles were regularly updated.

In the meantime, similar reports have been produced for the bibliometric assessment of two faculties with great success.

\section{Lessons learned and conclusions}

According to the philosophy of our department, bibliometrics is not only a helpful evaluation instrument contributing to complement and reinforce the peer review system. It should also be perceived as a compass for researchers in the 'publish or perish' dilemma in order to increase general visibility and to optimize publication strategies.

This philosophy has proven to be valid throughout the whole assessment exercise.

The initial interviews as well as the follow-up discussions with the researchers under evaluation fostered a win-win situation for both, researcher and bibliometrician, alike.

Table 3. Overview of the research fields analysed

\begin{tabular}{|l|c|}
\hline \multicolumn{1}{|c|}{ Research field } & \# reports \\
\hline Microbiology & 3 \\
\hline Economics & 3 \\
\hline Psychology & 2 \\
\hline Computer science & 2 \\
\hline Astrophysics & 2 \\
\hline Political science & 1 \\
\hline Mineralogy and crystallography & 1 \\
\hline Structural and computational biology & 1 \\
\hline Botany and Biodiversity research & 1 \\
\hline Pharmacy & 1 \\
\hline Enviromnental geosciences & 1 \\
\hline Sociology & 1 \\
\hline Food chemistry & 1 \\
\hline Computational physics & 1 \\
\hline Gravitational physics & 1 \\
\hline Particle physics & 1 \\
\hline Inorganic chemistry & 1 \\
\hline Physics & 1 \\
\hline Limnology & 1 \\
\hline Biophysical chemistry & 1 \\
\hline Zoology & 1 \\
\hline Sport science & 1 \\
\hline Mathematics & 1 \\
\hline Ecogenomics and systems biology & 1 \\
\hline Materials physics & 1 \\
\hline
\end{tabular}


All researchers could finally embrace the advantages of a thorough bibliometric report. Thus the bibliometric assessment exercise transformed for them from a nuisance to a valuable asset.

On the other hand we bibliometricians gained insight into many interesting aspects of a researcher's daily routine and learned much about discipline-specific publication habits.

Bibliometric expertise was not only appreciated by all researchers, but also by administrative staff and the peers. Its usefulness was generally confirmed and particularly emphasized for the life sciences. The positive experience gained in the social sciences is encouraging for our department to further explore suitable assessment procedures for researchers in the humanities.

Individual assessment is certainly complex and time-consuming. However, the valuable information produced can provoke positive changes at individual level, which in the long run are also beneficial for the institution itself. In terms of institutional visibility, the outcome can even be enhanced by policies (affiliation policy, publication strategy policy, open access policy, etc.), which -to come full circle- take effect at individual level.

\section{We bibliometricians gained insight into many interesting aspects of a researcher's daily routine and learned much about discipline-specific publica- tion habits}

Our suggested bibliometric report offers several advantages, which are highlighted below:

- It avoids complicated composite indicators, but rather relies on single indicators, which are particularly easy to understand for the researchers, the peers and administrative staff.

- Its multidimensional approach sheds light on various aspects, such as coverage, activity, visibility, impact, cooperation, research focus and knowledge base. It thus paints a diverse picture of a researcher's publication output.

- The practised inclusion and comparison of different data sources is helpful to identify and correct indexing and coverage errors.

- Finally, visualization (by means of network maps) helps to identify relevant clusters and fosters a better understanding of complex circumstances.

As a reputable service we do not only highlight the benefits but also the limitations of bibliometrics as an assessment method. It cannot be stressed enough that only quantitative aspects are measured in such a bibliometric assessment exercise. These are certainly objective per se, but should never be taken out of context. Each researcher is unique and has a particular history and individual skills. Just as each discipline has a particular publication culture. This should always be taken into account whenever peers set the course for the future career path of researchers. It is certainly irresponsible to exclusively rely on (unfortunately often practised "quick and dirty") bibliometrics and ignoring the big picture.
Last, but not least, our experience illustrates the crucial role modern scientific libraries are predestined to play in research assessment exercises. The field of bibliometrics is ideal for academic librarians to strengthen their on-campus position. Bibliometrics offers a wealth of opportunities to provide innovative services for both academic and administrative university staff. In so doing, librarians can actively contribute to the development of new publication strategies and the advancement of innovation.

It is irresponsible to exclusively rely on (unfortunately often practised "quick and dirty") bibliometrics and ignoring the big picture

\section{Notes}

1. Analyses in GS should be taken with a pinch of salt. GS is rather a search engine than a database, and therefore indexing remains non-transparent and documentation is lacking.

2. 'Publish or Perish' is a software programme that retrieves and analyses academic citations. It uses GS to obtain the raw citations (see also, http://www.harzing.com/pop.htm)

3. Another possibility would be to consider the JIF in the JCR edition corresponding to the publication year. However, this method is also not completely correct, since the JCR edition is always one year delayed and the calculation of the JIF considers either the two years or five years prior to the publication year (Gorraiz et al., 2012b). A third possibility would be to use the mean value of the impact factor from all publication years.

4. If the journal has been assigned to several WoS categories, the best quartile is used. This decision aims to help the researcher, who could always argue that multiple assignments are discriminatory.

5. The standard deviation is provided only upon request.

6. The "Category Normalized Citation Impact" (CNCl) provides the citation impact (citations per paper) normalized for subject, year and document type and is calculated according to the data collected via InCites. It is also named "Crown Indicator" or "Field Citation Score".

\section{Number of publications with at least 10 citations}

8. Usually, a table shows the top 10 out of the total number of citing journals (X1), of citing countries (X2), of citing institutions (X3), citing authors (X4) and includes the number and percentage of citing documents.

\section{Acknowledgements}

The authors wish to acknowledge Ursula Ulrych, Steve Redeing and our Department for Quality Assurance as well as all the researchers under evaluation for their much valued support and input.

\section{References}

Alonso, Sergio; Cabrerizo, Francisco-Javier; Herrera-Viedma, Enrique; Herrera, Francisco (2009). "H-index: A review 
focused in its variants, computation and standardization for different scientific fields". Journal of informetrics, v. 3, n. 4, pp. 273-289.

https://doi.org/10.1016/j.joi.2009.04.001

Bach, Jean-François (2011). On the proper use of bibliometrics to evaluate individual researchers. Académie des sciences.

http://www.academie-sciences.fr/pdf/rapport/avis170111gb. $p d f$

Bar-llan, Judit (2008). "Which h-index? A comparison of WoS, Scopus and Google Scholar". Scientometrics, v. 74, n. 2, pp. 257-271.

https://doi.org/10.1007/s11192-008-0216-y

Bauer, Bruno; Ferus, Andreas; Gorraiz, Juan; Gründhammer, Veronika; Gumpenberger, Christian; Maly, Nikolaus; Mühlegger, Johannes-Michael; Preza, José-Luis; SánchezSolís, Bárbara; Schmidt, Nora; Steineder, Christian (2015). Researchers and their data. Results of an Austrian surveyReport 2015. Version 1.2.

https://doi.org/10.5281/zenodo.34005

https://phaidra.univie.ac.at/o:40931

Bornmann, Lutz (2014). "Do altmetrics point to the broader impact of research? An overview of benefits and disadvantages of altmetrics". Journal of informetrics, v. 8, n. 4, pp. 895-903.

https://doi.org/10.1016/j.joi.2014.09.005

http://arxiv.org/abs/1406.7091

Bornmann, Lutz; De Moya-Anegón, Félix; Leydesdorff, Loet (2012). "The new excellence indicator in the World Report of the SCImago Institutions Rankings 2011". Journal of informetrics, v. 6, n. 2, pp. 333-335.

https://doi.org/10.1016/j.joi.2011.11.006

Costas, Rodrigo; Meijer, Ingeborg; Zahedi, Zohreh; Wouters, Paul (2012). The value of research data-Metrics for data sets from a cultural and technical point of view. A Knowledge Exchange Report.

http://www.knowledge-exchange.info/datametrics

Costas, Rodrigo; Bordons, María; Van Leeuwen, Thed N.; Van Raan, Anthony F. J. (2009). "Scaling rules in the science system: influence of field-specific citation characteristics on the impact of individual researchers". Journal of the American Society for Information Science and Technology, v. 60, n. 4, pp. 740-753.

https://doi.org/10.1002/asi.21017

Cronin, Blaise (1984). The citation process. The role and significance of citations in scientific communication. London: Taylor Graham. ISBN: 0947568018

De Bellis, Nicola (2009). Bibliometrics and citation analysis: From the Science Citation Index to cybermetrics. Lanham, MD: Scarecrow Pr. ISBN: 9780810867133

De Nooy, Wouter; Mrvar, Andrej; Batagelj, Vladimir (2005). Exploratory social network analysis with Pajek. Structural analysis in the social sciences (n. 27). Cambridge: Cambridge University Press. ISBN: 9780521174800

Galligan, Finbar; Dyas-Correia, Sharon (2013). Altmetrics:
Rethinking the way we measure. Serials review, v. 39, n. 1, pp. 56-61.

https://doi.org/10.1016/j.serrev.2013.01.003

Garfield, Eugene (2005). "The agony and the ecstasy. The history and meaning of the journal impact factor".

http://garfield.library.upenn.edu/papers/jifchicago2005. $p d f$

Glänzel, Wolfgang (2014). Analysis of co-authorship patterns at the individual level. Transinformação, v. 26, n. 3, pp. 229-238.

https://doi.org/10.1590/0103-3786201400030001

Glänzel, Wolfgang; Chi, Pei-Shan; Gumpenberger, Christian; Gorraiz, Juan (2016). "Information sources - information targets: evaluative aspects of the scientists' publication strategies". Procs of the $21^{\text {st }}$ Int/ conf on science and technology indicators, València (Spain), September 14-16, 2016. http://dx.doi.org/10.4995/STI2016.2016.4543

http://ocs.editorial.upv.es/index.php/STI2016/STI2016/ paper/viewFile/4543/2327

Glänzel, Wolfgang; Debackere, Koenraad; Thijs, Bart; Schubert, András (2006). "A concise review on the role of author self-citations in information science, bibliometrics and science policy". Scientometrics, v. 67, n. 2, pp. 263-277. https://doi.org/10.1007/s11192-008-2109-5

Glänzel, Wolfgang; Moed, Henk F. (2002). "Journal impact measures in bibliometric research". Scientometrics, v. 53, n. 2, pp. 171-193.

https://doi.org/10.1023/A:1014848323806

Glänzel, Wolfgang; Thijs, Bart; Schlemmer, Balázs (2004). "A bibliometric approach to the role of author self-citations in scientific communication". Scientometrics, v. 59, n. 1, pp. 63-77.

https://doi.org/10.1023/B:SCIE.0000013299.38210.74

Glänzel, Wolfgang; Wouters, Paul (2013). "The do's and don'ts of individual-level bibliometrics". Position statement at the $14^{\text {th }}$ ISSI Conference, Vienna, 15-18 July 2013. In: Gorraiz et al. (eds.), Proceedings of the $14^{\text {th }}$ Intl Conf on Scientometrics and Informetrics, vol. 1. Vienna: ISSI.

http://www.issi2013.org/Images/ISSI_Proceedings_ Volume_l.pdf

González-Pereira, Borja; Guerrero-Bote, Vicente P.; DeMoya-Anegón, Félix (2009). "The SJR indicator: A new indicator of journals' scientific prestige".

http://arxiv.org/abs/0912.4141

Gorraiz, Juan; Gumpenberger, Christian (2015). “A flexible bibliometric approach for the assessment of professorial appointments". Scientometrics, v. 105, n. 3, pp. 1699-1719. https://doi.org/10.1007/s11192-015-1703-6

Gorraiz, Juan; Gumpenberger, Christian; Schlögl, Christian; Wieland, Martin (2012b). "On the temporal stability of Garfield's Impact Factor and its suitability to identify hot papers". Procs of STI 2012 Montreal. $17^{\text {th }}$ Int I Conf on Science and Technology Indicators, v. 1, pp. 319-332.

http://2012.sticonference.org/index.php?page $=$ proc

Gorraiz, Juan; Purnell, Philip J.; Glänzel, Wolfgang (2013). 
"Opportunities for and limitations of the Book citation index". Journal of the American Society for Information Science and Technology, v. 64, n. 7, pp. 1388-1398.

https://doi.org/10.1002/asi.22875

Gorraiz, Juan; Reimann, Ralph; Gumpenberger, Christian (2012a). "Key factors and considerations in the assessment of international collaboration: a case study for Austria and six countries". Scientometrics, v. 91, n. 2, pp. 417-433. https://doi.org/10.1007/s11192-011-0579-3

Gumpenberger, Christian; Wieland, Martin; Gorraiz, Juan (2012). "Bibliometric practices and activities at the University of Vienna". Library management, v. 33 , n. 3, pp. 174-183. http://dx.doi.org/10.1108/01435121211217199

Harzing, Anne-Wil (2016). Publish or Perish http://www.harzing.com/pop.htm

Haustein, Stephanie; Peters, Isabella; Bar-Ilan, Judit; Priem, Jason; Shema, Hadas; Terliesner, Jens (2014). "Coverage and adoption of altmetrics sources in the bibliometric community". Scientometrics, v. 101, n. 2, pp. 1145-1163. https://doi.org/10.1007/s11192-013-1221-3

Hirsch, Jorge E. (2005). "An index to quantify an individual's scientific research output". Proceedings of the National Academy of Sciences of the United States of America, v. 102, n. 46, pp. 16569-16572.

https://doi.org/10.1073/pnas.0507655102

Konkiel, Stacy (2013). "Altmetrics: a $21^{\text {st }}$ century solution to determining research quality". Online searcher, v. 37, n. 4, July/August.

http://www.infotoday.com/OnlineSearcher/Articles/ Features/Altmetrics-A-stCentury-Solution-to-DeterminingResearch-Quality-90551.shtml

Laudel, Grit (2002). "What do we measure by co-authorships?". Research evaluation, v. 11, n. 1, pp. 3-15. https://doi.org/10.3152/147154402781776961

Lotka, Alfred J. (1926). "The frequency distribution of scientific productivity". Journal of the Washington Academy of Sciences, v. 16, n. 12, pp. 317-323.

Moed, Henk F. (2005). Citation analysis in research evaluation. Dordrecht: Springer. ISBN: 9781402037139

Moed, Henk F. (2010). "The Source Normalized Impact per Paper is a valid and sophisticated indicator of journal citation impact". Journal of the American Society for Information Science and Technology, v. 62, n. 1, pp. 211-213. https://doi.org/10.1002/asi.21424

Moed, Henk F. (2011). "Measuring contextual citation impact of scientific journals". Journal of informetrics, v. 4, n. 3, pp. 265-277. http://dx.doi.org/10.1016/j.joi.2010.01.002

Moed, Henk F.; Halevi, Gali (2015). "Multidimensional assessment of scholarly research impact". Journal of the American Society for Information Science and Technology, v. 66, n. 10 , pp. 1988-2002.

https://doi.org/10.1002/asi.23314
Persson, Olle; Danell, Rickard; Schneider, Jesper-Wiborg (2009). "How to use BibExcel for various types of bibliometric analysis". In F. Åström, R. Danell, B. Larsen, J. Schneider (eds.), Celebrating scholarly communication studies: A festschrift for Olle Persson at his $60^{\text {th }}$ birthday (pp. 9-24). Leuven: International Society for Scientometrics and Informetrics. http://issi-society.org/ollepersson60/ollepersson60.pdf

Persson, Olle; Glänzel, Wolfgang; Danell, Rickard (2004). "Inflationary bibliometric values: the role of scientific collaboration and the need for relative indicators in evaluative studies". Scientometrics, v. 60, n. 3, pp. 421-432. https://doi.org/10.1023/B:SCIE.0000034384.35498.7d

Schubert, András; Braun, Tibor (1986). "Relative indicators and relational charts for comparative assessment of publication output and citation impact". Scientometrics, v. 9, n. 5-6, pp. 281-291.

https://doi.org/10.1007/BF02017249

Schubert, András; Braun, Tibor (1996). "Cross-field normalization of scientometric indicators". Scientometrics, v. 36, n. 3, pp. 311-324.

https://doi.org/10.1007/BF02129597

Shockley, William (1957). "On the statistics of individual variation of productivity in research laboratories". Procs of the Institute of Radio Engineers, v. 45, n. 3, pp. 279-290. https://doi.org/10.1109/JRPROC.1957.278364

Seglen, Per O. (1992). "The skewness of science". Journal of the American Society for Information Science, 4, pp. 628638.

Van Eck, Nees-Jan; Waltman, Ludo (2010). "Software survey: VOSviewer, a computer program for bibliometric mapping". Scientometrics, v. 84, n. 2, pp. 523-538 (paper, preprint, supplementary material) - See more at:

http://www.vosviewer.com/publications\#sthash.12u6KiZI. dpuf

Van Raan, Anthony F. J. (2004). "Measuring science. Capita selecta of current main issues". In: H. F. Moed, W. Glänzel; U. Schmoch (eds.), Handbook of quantitative science and technology research. The use of publication and patent statistics in studies of S\&T systems (pp. 19-51). Dordrecht: Kluwer Academic Publishing. https://goo.gl/gRR6lj

Vinkler, Peter (2010). The evaluation of research by scientometric indicators. Oxford: CP, Chandos Publishing. ISBN: 1843345722

Weingart, Peter (2005). "Impact of bibliometrics upon the science system: Inadvertent consequences?". Scientometrics, v. 62, n. 1, pp. 117-131.

https://doi.org/10.1007/s11192-005-0007-7

Wouters, Paul; Glänzel, Wolfgang; Gläser, Jochen; Rafols, Ismael (2013). "Individual-level evaluative bibliometrics - The politics of its use and abuse". Brief report at the STI 2013 plenary on the methodological aspects of individuallevel bibliometrics. Berlin, September 2013. 